\title{
There Is No Viable Path to Consensus Based on the Current Research Literature
} Katherine S. Corker

Ten years into the replication crisis, psychologists have learned that we need to do better. Many initiatives have been proposed and implemented to improve research practices, but a neglected domain for improvement has been changing incentives. The target article (Leising et al., in press) - henceforth called the Better Personality Science (BPS) Collaborative provides a concrete proposal for reshaping how we evaluate research, which they propose will better align incentives and improve research quality. I suspect other commentaries will focus their critiques on the particulars of the proposed point system for scoring research quality, which, although laudable for its specificity, contains some shortcomings related to its ability to properly reward research beyond very common research designs.

I will instead focus on where the target paper differs from other papers in this genre: its focus on fostering consensus. The BPS Collaborative proposes that "the field cannot go on without greater and more explicit consensus as to (1) what the most important issues to be investigated are, (2) how things shall be named, (3) how things shall be measured, (4) how data shall be analyzed, and (5) what the current state of theory and knowledge is" (p. 8). Given this focus on consensus, I was surprised that the BPS paper gave only scant attention to metaanalysis, which is often upheld as a consensus building tool (Chan \& Arvey, 2012). Here, I explain why meta-analysis has often failed to create consensus, illuminating a more general flaw in the BPS Collaborative's vision of consensus building, and I describe what we should do instead to achieve a more cumulative psychology.

Meta-analysis is a tool for providing summaries of sets of studies, both in terms of central tendency (what a typical study looks like) and variability (how much studies vary from one another). Furthermore, meta-analysis is the quantitative part of a broader research synthesis method known as systematic review. Systematic reviews are designed to take stock of all current knowledge on particular research questions, and they involve a repeatable, comprehensive search strategy, coupled with evidence quality evaluation. Systematic reviews may include meta-analyses, but they can also be qualitative (see Corker, in press, for additional discussion on strengths and weaknesses of both methods).

As such, systematic reviews and meta-analyses seem to be promising candidates for establishing consensus in a given research area. Indeed, Chan and Arvey (2012) said as much: "Meta-analysis may contribute to the advancement of knowledge and normal science ... by facilitating the building of consensus in a field or topic" (p. 85). The idea is that a review will provide a birds-eye overview of current evidence on a topic, showing where consensus vs. disagreement exists in the knowledge base. Interestingly, although consensus would seem to be an unabashed good, historically there have been worries that meta-analyses would provide too definitive an answer to a question. If strong consensus was revealed through a metaanalysis, further research on a topic might be quelched: "Meta-analyses may declare a 'winner' or 'loser' before an ongoing trial is over" (Feinstein, 1995, p. 77).

Although promising as a consensus building tool, the reality of meta-analysis is less sanguine. Anyone who has attempted to perform a meta-analysis or systematic review will report how frustrating it is to discover how idiosyncratically researchers work. In most areas of psychology, there is little overlap between studies in terms of measurement, methodology, and 
even theoretical approach. Crucially, the lack of commonalities between studies sometimes makes synthesis well-nigh impossible. How can the results of such studies even begin to be combined?

The BPS Collaborative laments this exact state of affairs and proposes that we reward those who build consensus positions and use consensual methods in their research to encourage the proliferation of this kind of work. A researcher eager to adopt the BPS Collaborative's recommendations might therefore gather several research groups together to engage in a meta-analysis or systematic review, with the goal of uncovering the group's collective understanding of knowledge on a research question. But our eager colleague would almost immediately be met with a problem: in the presence of such diversity in measurement, methods, and theory, exactly where is consensus supposed to come from?

Put succinctly, my argument is the following. Given the current state of affairs in psychology - in which $50 \%$ or more of our results fail to replicate, the vast majority of measures are ad hoc or of unknown validity, theories are so vague as to be mostly unfalsifiable, and there is little to no overlap in approach between studies in supposedly related topical areas - neither meta-analysis nor any other currently known consensus generating procedure is going to be sufficient to allow us to fashion gold from lead.

If true, where does that leave us? Before we "quit the academy and make an honest living selling shoes" (Meehl, 1990, p. 237), we might consider the alternative course proposed by Paul Rozin twenty years ago. Rozin (2001) argued that detailed, precise descriptions of reliably occurring social phenomena should be the basis for later experimentation and model testing. In contrast with biology and other developed sciences, he argued, psychologists have often jumped straight to hypothesis testing and skipped over the rich observational research that could inform and shape those experiments.

Certainly, it could be argued that personality psychology has valued this kind of descriptive work more than some other subfields of psychology. Indeed, the existence of the Big Five as an organizing framework is a testament to how generative careful descriptive work can be. But given our current levels of progress and understanding, we could surely do even more such work. Is my argument a call for totally atheoretical, inductive work? No, because even descriptive work is theory-laden and must begin somewhere (Oreskes, 2019). But if theories are explanations of available facts, then to strengthen our theories - and therefore our consensual understanding - it would be nice to first have some reliable facts to explain. But attempting to jump straight to consensus on the basis of our current (highly flawed) research literature, as the BPS Collaborative recommends, is likely to fail.

\section{References}

Chan, M. E., \& Arvey, R. D. (2012). Meta-analysis and the development of knowledge. Perspectives on Psychological Science, 7(1), 79-92. https://doi.org/10.1177/1745691611429355

Corker, K. S. (In press). Strengths and weaknesses of meta-analysis. In L. Jussim, S. Stevens, \& J. Krosnick (Eds.) Research integrity in the behavioral sciences. Oxford University Press. https://doi.org/10.31234/osf.io/6gcnm 
Feinstein, A. R. (1995). Meta-analysis: Statistical alchemy for the 21st century. Journal of Clinical Epidemiology, 48, 71-79. https://doi.org/10.1016/0895-4356(94)00110-C

Leising, D., Thielmann, I., Glöckner, A., Gärtner, A., Schönbrodt, F. (In press). Ten steps toward a better personality science - How quality may be more rewarded in research evaluation. Personality Science.

Meehl, P. E. (1990). Why summaries of research on psychological theories are often uninterpretable. Psychological Reports, 66(1), 195-244. https://doi.org/10.2466/pr0.1990.66.1.195

Oreskes, N. (2019). Oreskes, N. (2019). Why trust science? Perspectives from the history and philosophy of science. In Why Trust Science? (pp. 15-68). Princeton University Press. https://doi.org/10.1515/9780691189932-003

Rozin, P. (2001). Social psychology and science: Some lessons from Solomon Asch. Personality and Social Psychology Review, 5(1), 2-14. https://doi.org/10.1207/S15327957PSPR0501 1 